\title{
Double-carbapenem therapy in the treatment of multidrug resistant Gram- negative bacterial infections: a systematic review and meta-analysis
}

Yuan-yuan Li ${ }^{1,2}$, Jin Wang ${ }^{1}$, Rui Wang ${ }^{1}$ and Yun Cai ${ }^{1 *}$

\begin{abstract}
Background: To compare the efficacy and safety of double-carbapenem therapy (DCT) with other antibiotics for the treatment of multidrug resistant (MDR) Gram-negative bacterial infections.

Methods: Cochrane Library, PubMed, Embase and Web of Science as well as Chinese databases were searched from database establishment to February 2019. All types of studies were included if they had evaluated efficacy and safety of DCT regimens in patients with MDR Gram-negative bacterial infections. Clinical response, microbiological response, adverse events and mortality were the main outcomes. The protocol was registered with PROSPERO No. CRD42019129979.

Results: Three cohort or case-control studies consisting of 235 patients and 18 case series or case reports consisting of 90 patients were included. The clinical and microbiological responses were similar between DCT and other regimens in patients with carbapenem-resistant Enterobacteriaceae (CRE) infection. DCT achieved a lower mortality than comparators in patients with $C R E$ infection $(O R=0.44,95 \% \mathrm{Cl}=0.24-0.82, P=0.009)$. Ertapenem was the most reported antibiotic in DCT regimens in case series or case reports. Moreover, clinical and microbiological improvements were found in $59(65.6 \%)$ and $63(70 \%)$ in total 90 cases, respectively.

Conclusions: DCT was as effective as other antibiotics in treating MDR Gram-negative bacterial infections, with similar efficacy response and lower mortality. DCT could be an alternative therapeutic option in the treatment of MDR Gram-negative bacterial infections. High-quality randomized controlled trials were required to confirm the beneficial effects of DCT.
\end{abstract}

Keywords: Double-carbapenem therapy, Antibiotics, Carbapenem-resistant Enterobacteriaceae, Multidrug resistant, Meta-analysis

\footnotetext{
*Correspondence: caicai_hh@126.com

${ }^{1}$ Center of Medicine Clinical Research, Department of Pharmacy, PLA General Hospital, 28 Fu Xing Road, Beijing 100853, People's Republic of China

Full list of author information is available at the end of the article
}

(c) The Author(s). 2020 Open Access This article is licensed under a Creative Commons Attribution 4.0 International License, which permits use, sharing, adaptation, distribution and reproduction in any medium or format, as long as you give appropriate credit to the original author(s) and the source, provide a link to the Creative Commons licence, and indicate if changes were made. The images or other third party material in this article are included in the article's Creative Commons licence, unless indicated otherwise in a credit line to the material. If material is not included in the article's Creative Commons licence and your intended use is not permitted by statutory regulation or exceeds the permitted use, you will need to obtain permission directly from the copyright holder. To view a copy of this licence, visit http://creativecommons.org/licenses/by/4.0/. The Creative Commons Public Domain Dedication waiver (http://creativecommons.org/publicdomain/zero/1.0/) applies to the data made available in this article, unless otherwise stated in a credit line to the data. 


\section{Background}

Carbapenem antibiotics (including imipenem, meropenem, ertapenem and doripenem), with a broad spectrum of antibacterial activity, play an extremely important role in the field of anti-infective treatment for severe infections. They are stable against most chromosomal broadspectrum beta-lactamases and cephalosporinases found in Gram-negative bacteria [1, 2]. However, with the wide application of carbapenem antibiotics, carbapenemhydrolyzing beta-lactamases, also named carbapenemases, have been increasingly found in Gram-negative pathogens. These beta-lactamases may limit the use of carbapenem antibiotics and cause treatment failure in severe infections [3, 4]. Carbapenemases, accompanied with drug resistance, constantly threat global health [5].

Carbapenemases belong to Ambler class A, B or D beta-lactamases and are mostly produced by Enterobacteriaceae, Pseudomonas aeruginosa or Acinetobacter baumannii [6, 7]. Class A carbapenemases can effectively hydrolyze carbapenem antibiotics by binding on active-site serine. These carbapenemases include the members of SME (Serratia marcescens enzyme), NMC (non-metallo enzyme carbapenemase), IMI (imipenemhydrolyzing), GES (Guiana extended spectrum) and the most important KPC (Klebsiella pneumoniae carbapenemase) beta-lactamases [8]. Class B carbapenemases are also called Metallo-beta-lactamases (MBLs). These zincdependent enzymes can hydrolyze beta-lactams and are not inhibited by beta-lactamase inhibitors. Class B carbapenemases include IMP (imipenemase), VIM (Verona integron-encoded MBL), SPM (Sao Paulo MBL), GIM (German imipenemase) and NDM (New Delhi MBL) groups $[9,10]$. They are mainly detected in $P$. aeruginosa and Enterobacteriaceae [11]. Class D carbapenemases are primarily detected in A. baumannii and Enterobacteriaceae (especially $K$. pneumoniae). They consist of oxacillinases (OXAs) which prefer to hydrolyze oxacillin or cloxacillin at higher rates than penicillin. Most members of OXAs are not susceptible to beta-lactamase inhibitors, but may be inhibited by $\mathrm{NaCl}[12,13]$.

For carbapenem-resistant Gram-negative bacteria, there are limited antimicrobial treatment options [14, 15]. Novel beta-lactam/beta-lactamase inhibitors (such as ceftazidime/avibactam) may be available treatment options, while poor use and rapid emergence of resistance restrict their application [16, 17]. With less effective monotherapy and increasing resistance, evidence of retrospective studies on combination therapy of Gramnegative bacterial infections is increasing [18-20]. Many combination therapies have shown better survival and mortality reduction compared with monotherapy regimens, especially patients with a high predicted mortality [21-23]. The carbapenem-based combination regimens exert good synergistic results and low resistance $[24,25]$.
In these combination regimens, double-carbapenem therapy (DCT) is first attempted in three Greek patients in 2013 [26]. This study demonstrated bactericidal effect and clinical success of DCT and attributed to inactivating carbapenemases made by one carbapenem, mainly ertapenem. Since then, more and more clinical studies about DCT have been reported, while its effectiveness and safety have not been comprehensively addressed. In the present systematic review and meta-analysis, we aimed to evaluate efficacy and safety of DCT and other antibiotic regimens in patients with multidrug resistant (MDR) Gram-negative bacterial infections.

\section{Methods}

This meta-analysis followed the Preferred Reporting Items for Systematic Reviews and Meta-analysis (PRISMA) guidelines [27] and was registered to PROSPERO (No. CRD42019129979) [28].

\section{Search method and data extraction}

Literature search was performed in English databases, including Cochrane Library, PubMed, Embase and Web of Science, and Chinese databases, including SinoMed, CNKI and WANFANG MED DATA, from database establishment to February 3rd, 2019. No restrictions on language and geographic region were applied. Screening of abstract and full text was independently performed by two authors (YYL and JW). Search terms were set as "Double carbapenem", "Dual carbapenem", "Carbapenem" AND "Double", "Carbapenem" AND "Dual", "Carbapenem" AND "Joint", "Carbapenem" AND "Combination". Reference lists of included articles and relevant reviews were also searched.

In order to ensure accuracy, data extraction was independently carried out by two authors (YYL and JW). Controversial issues were resolved by consensus. When necessary, the corresponding authors were requested to provide unpublished data via e-mail. The following information was extracted: first author name, publication year, region, study design, characteristics of patients (sample size, sex and age), type of infection, type of organism, administered antibiotics, antimicrobial susceptibility test, treatment duration, follow-up time and outcomes.

\section{Inclusion and exclusion criteria}

Randomized controlled trials (RCTs), cohort and casecontrol studies as well as case series and case reports were included. Studies focusing on patients with MDR Gramnegative bacterial infections were considered eligible for the meta-analysis, if such studies had reported available data of clinical response, microbiological response, adverse events, or mortality for the treatment of DCT. Studies which contained DCT in both treatment and control 
groups were excluded. Studies on experimental animal models and in vitro studies were excluded.

\section{Quality assessment}

Regarding risk of bias, the quality of each selected RCT was independently assessed by the two authors with the Cochrane Collaboration's tool [29]. The non-randomized studies were assessed with the Newcastle-Ottawa Scale (NOS) [30]. The risk of bias was evaluated as low, median or high by assigning or scoring each item separately. Any differences were resolved through consensus.

\section{Definitions and outcomes}

The definitions of infections in the current meta-analysis were based on the definitions provided by the individual studies. The outcomes mainly focused on the efficacy and safety of DCT, including clinical response, microbiological response, adverse events and mortality. Clinical response was defined as resolution of clinical signs and symptoms of the infections by therapy completion. Microbiological response was defined as the absence of pathogens from subsequent specimen cultures.

\section{Statistical analysis}

Meta-analysis was performed by Review Manager 5.3. Odds ratios (ORs) were calculated as effect measures, and $P<0.05$ was considered as statistically significant.
The fixed effects model was used to obtain pooled estimates of ORs, including 95\% confidence interval (CI) [31]. Statistical heterogeneity was tested by $\square^{2}$ test $(P \leq$ 0.10 to indicate statistically significant) and quantified using $\mathrm{I}^{2}$ statistics [32]. Subgroup and sensitivity analyses were performed according to treatment regimens in control groups. The publication bias was assessed through visual inspection of funnel plot.

\section{Results}

\section{Study identification}

A total of seven databases and 1972 unique references were initially identified. Overall, 28 studies were selected for fulltext review, and 21 studies met our inclusion criteria. For these 21 studies, three trials [33-35] were cohort or casecontrol studies, and 18 reports [26, 36-52] were case series or case reports. The flow diagram (Fig. 1) showed the detailed screening and selection process for the trials included in our analysis. Table 1 summarized the basic characteristics of cohort or case-control studies included, and such information for case series or case reports was performed in Table 2. Our study covered patients with MDR Gramnegative bacterial infections, and DCT was used to compare with other available antibiotics.

The three cohort or case-control studies were composed of 235 patients with carbapenem-resistant Enterobacteriaceae (CRE) infection. Colistin, tigecycline and

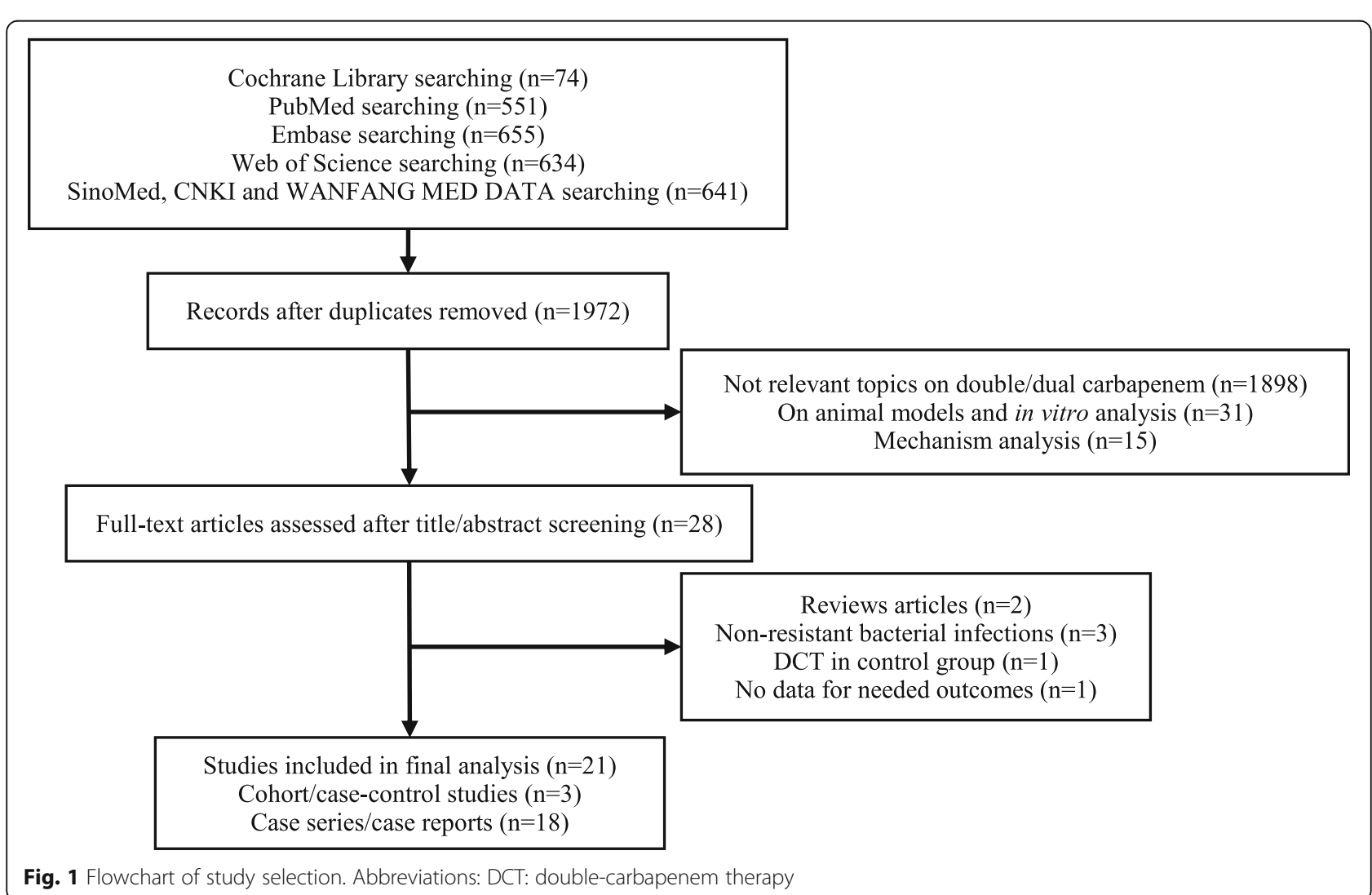




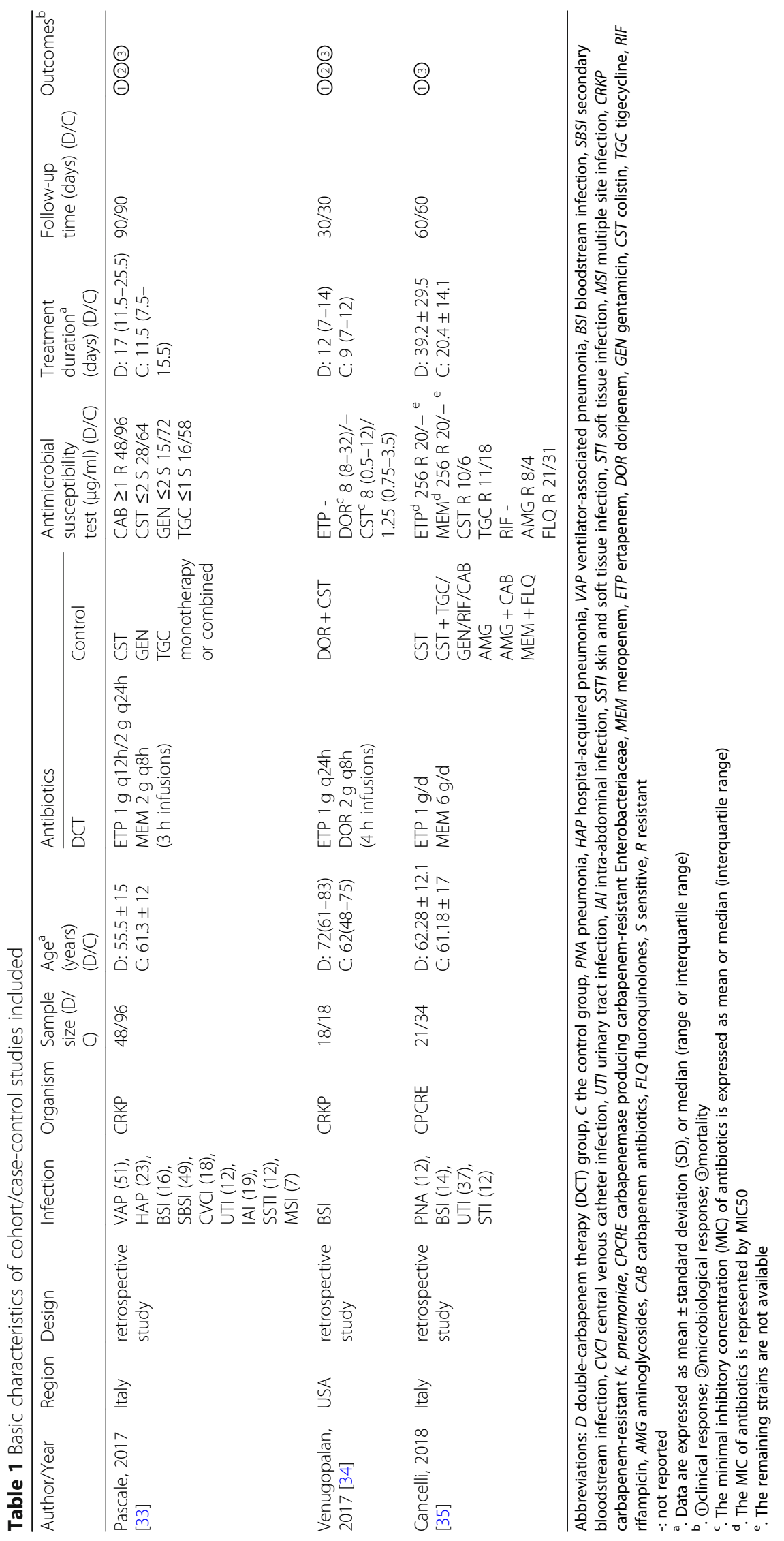




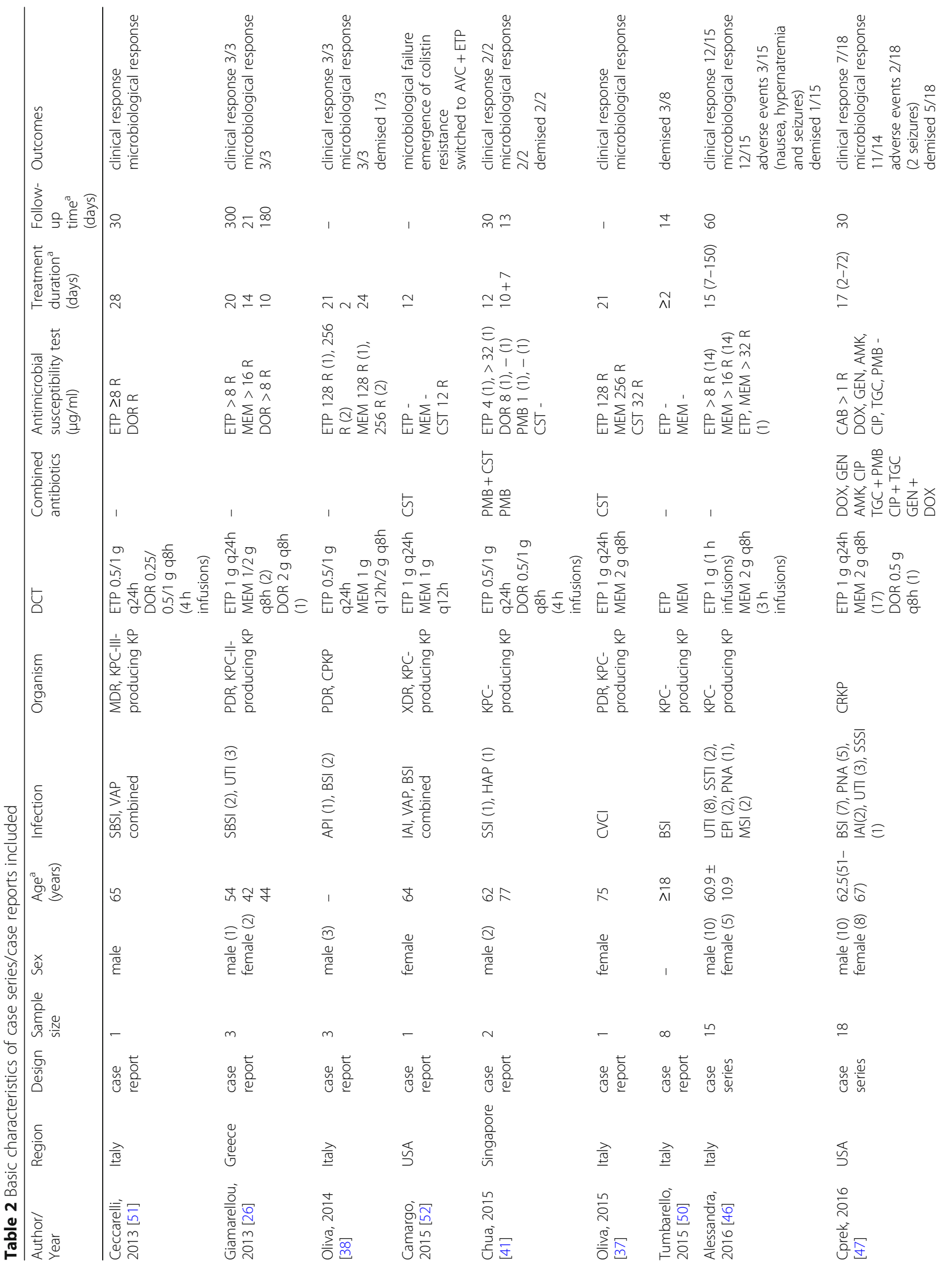




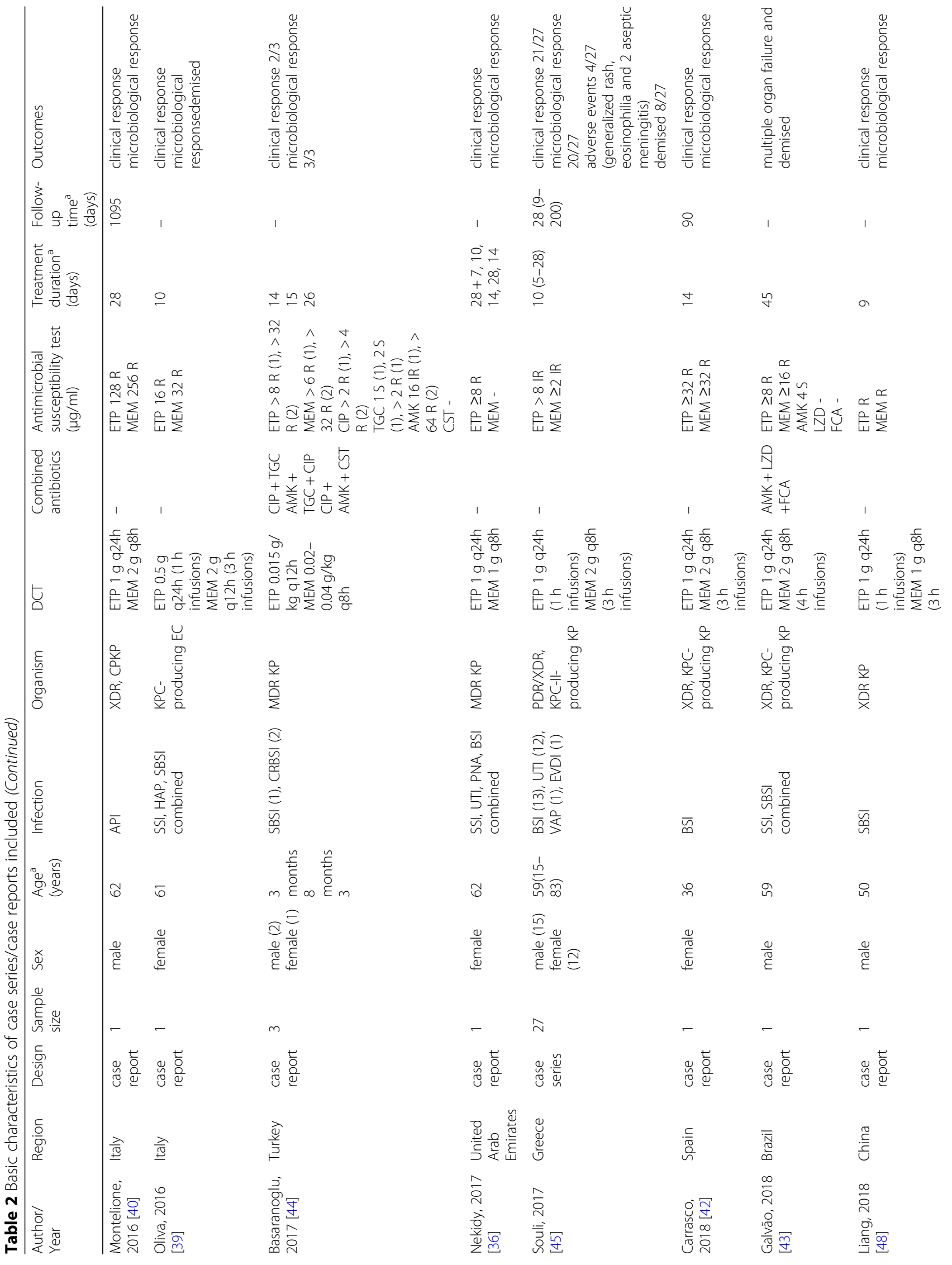




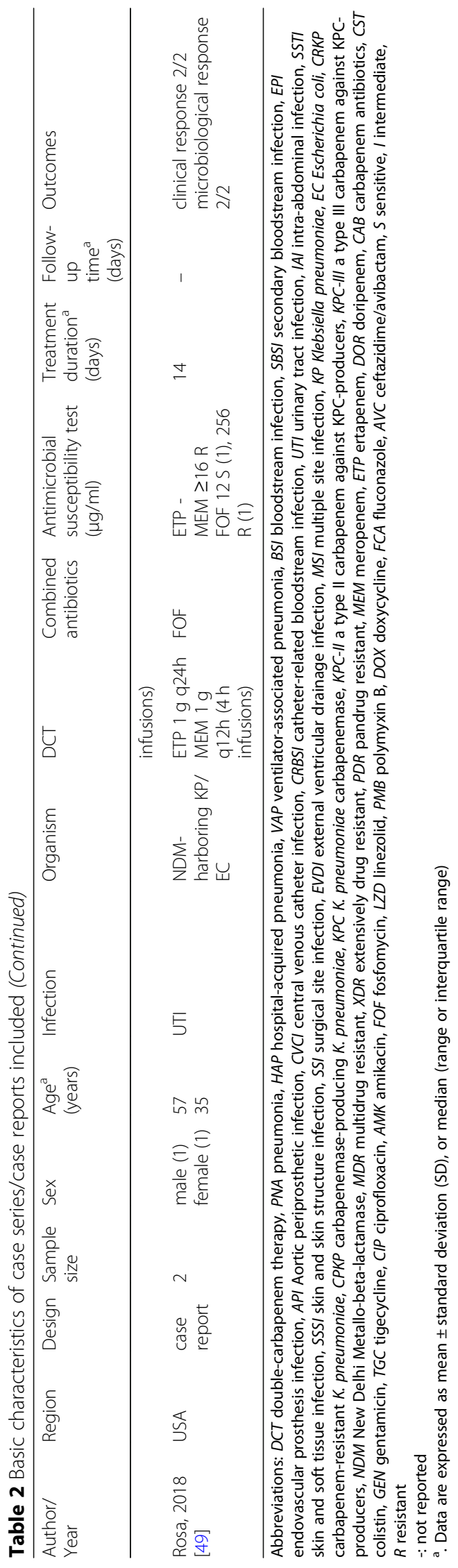


aminoglycoside (especially gentamicin) monotherapies or combined regimens were compared with DCT in all patients. DCT regimens included ertapenem+meropenem and ertapenem+doripenem. Ertapenem was used at a daily dose of $1-2 \mathrm{~g}$. Meropenem and doripenem were administered every $8 \mathrm{~h}$ at a high dose $(2 \mathrm{~g})$, mainly adopting the extended infusion. Dose was adjusted according to creatinine clearance if renal function was abnormal.

\section{Study quality}

The NOS assessment tool included three subjects as follows: the selection of study groups, the comparability between the groups and the ascertainment of exposure or outcome. Studies with a score of 7-9 were considered as high-quality studies [53, 54]. Table 3 summarized the risk of bias. All studies in our meta-analysis had high qualities (7 score) and low risk for sequence generation and allocation concealment.

\section{Clinical response}

The data pooling from three studies consisting of 235 patients reported no significant difference between DCT-treated patients and those treated with other antibiotics $(\mathrm{OR}=1.74,95 \% \mathrm{CI}=0.99-3.06, P=0.05)$ (Fig. 2).

\section{Microbiological response}

Two studies consisting of 158 patients had reported the microbiological response. No significant difference was detected in patients with CRE infection between DCT and control groups $(\mathrm{OR}=1.90,95 \% \mathrm{CI}=0.95-3.80$, $P=0.07$ ) (Fig. 3).

\section{Adverse events}

No studies had recorded adverse events.

\section{Mortality}

Three studies consisting of 233 patients had reported the mortality with $30 \sim 60$ days of follow-up visit. Compared with the control groups, DCT showed a lower mortality in patients with CRE infection (OR $=0.44,95 \%$ $\mathrm{CI}=0.24-0.82, P=0.009$ ) (Fig. 4).

\section{Summary of case series or case reports}

A total of 18 case series or case reports composed of 90 patients were assessed. DCT regimens mainly consisted of ertapenem+meropenem and ertapenem+doripenem. Infection types included pneumonia, bloodstream infection, urinary tract infection, intra-abdominal infection, skin infection, surgical site infection and so on. The number of patients with bloodstream infection was the highest (31 patients, 34.4\%). Followed by urinary tract infection (26 patients, 28.9\%). The infections were primarily caused by MDR K. pneumoniae. Among 90 patients, clinical response was reported in $59(65.6 \%)$ patients, while microbiological response was found in 63 (70\%) patients. In patients with bloodstream infection, clinical and microbiological responses were 16/31 (51.6\%) and 20/31 (64.5\%), respectively. While both clinical and microbiological responses were $21 / 26(80.8 \%)$ in patients with urinary tract infection. Nine cases of adverse events were reported, including seizures (three cases), aseptic meningitis (two cases), generalized rash (one case), eosinophilia (one case), nausea (one case) and hypernatremia (one case). The number of patients demised was $22(24.4 \%)$, and 10 cases of them were reported to decease in spite of clinical or microbiological improvement.

\section{Discussion}

In 2011, Bulik and Nicolau [55] first proposed the idea of DCT against KPC-producing $K$. pneumoniae by in vitro and mouse thigh infection model experiments. In 2013, Giamarellou et al. [26] reported that DCT successfully cured three patients with bloodstream infection and urinary tract infection caused by KPC-producing $K$. pneumoniae. Since then, DCT had been increasingly reported in clinical studies, no matter case series or case reports, cohort or case-control studies. Unfortunately, there were no RCTs available so far. To the best of our knowledge, our research was the first systematic review and meta-analysis of DCT to date, though two reviews had reported parts of DCT-treated patients with CRE infection. Our study contained three cohort or casecontrol studies consisting of 235 patients with CRE infection and 18 case series or case reports consisting of 90 patients. Most patients suffered from critical infections. The infection types mainly included pneumonia, bloodstream infection and urinary tract infection. Generally, the patients tolerated DCT regimens well. Only three case series had reported nine cases of adverse events, mainly including seizures and meningitis.

Table 3 Risk of bias assessed by NOS assessment tool

\begin{tabular}{|c|c|c|c|c|c|}
\hline Author/Year & Design & Selection & Comparability & $\begin{array}{l}\text { Outcome } \\
\text { /Exposure }\end{array}$ & $\begin{array}{l}\text { NOS } \\
\text { score }\end{array}$ \\
\hline Pascale, 2017 & case-control study & & & & 7 \\
\hline Venugopalan, 2017 & cohort study & & & & 7 \\
\hline Cancelli, 2018 & cohort study & & & & 7 \\
\hline
\end{tabular}




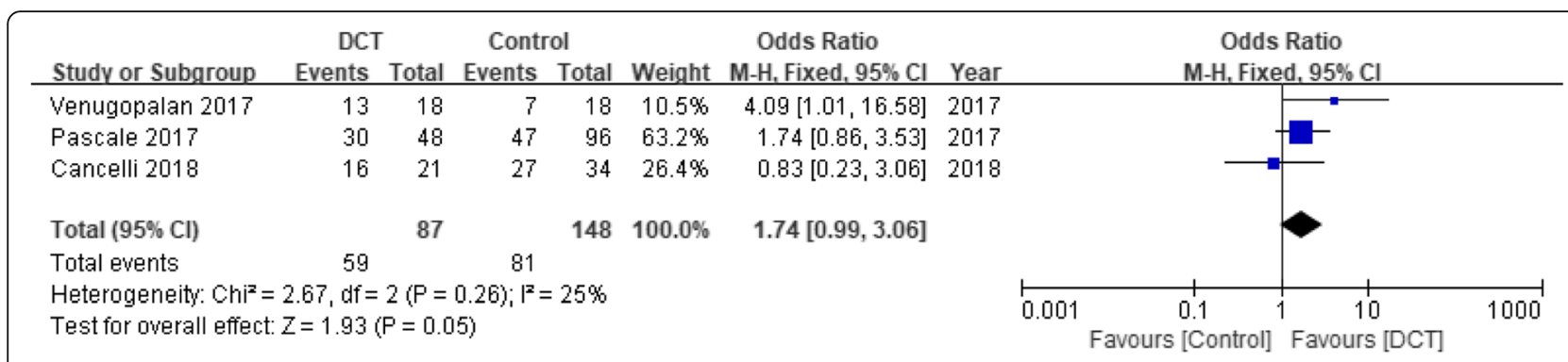

Fig. 2 Forest plot of clinical response for patients with CRE infection. Abbreviations: CRE: carbapenem-resistant Enterobacteriaceae; Cl: confidence interval

Moreover, none of the adverse events led to interruption of treatment. Our meta-analysis demonstrated that though no obvious advantages in clinical and microbiological responses were noticed, the mortality in DCT regimens was lower compared with the control groups for CRE infection. In case series or case reports, ertapenem-containing regimens were the main pattern of DCT, which were applied to complicated severe infections caused by MDR Gram-negative bacteria. Our result was consistent with previous published reviews of DCT for the treatment of carbapenemase-producing K. pneumoniae caused critical infections [56] or CRE caused bloodstream infection [57] which both suggested that DCT regimens might be an effective and safe strategy to treat carbapenemase-producing K. pneumoniae or CRE. Moreover, White et al. [57] also revealed DCT exhibited lower mortality in the treatment of CRE bloodstream infection compared with polymyxin-based regimens. Oliva A et al. [58] compared DCT + colistin with DCT for the treatment of 32 patients with multiple infections caused by carbapenem-resistant $K$. pneumoniae. The result did not support that DCT + colistin was superior to DCT alone with similar clinical response and mortality in both groups.

DCT regimens have been proven to be effective in many in vitro and animal studies. In vitro studies [59, 60] have confirmed the synergistic effects of DCT regimens against carbapenemase-producing $K$. pneumoniae. Another in vitro study [61] has evaluated the synergistic activity of 10 double or triple combination regimens based on meropenem against carbapenemase-producing
K. pneumoniae. The results show that the combination of meropenem and ertapenem is the most effective strategy in double combination regimens. DCT against MDR Gram-negative bacterial infections has also been supported by animal model data. The combination of ertapenem and doripenem has been observed to statistically decrease the bacterial density compared with doripenem monotherapy in a mouse thigh model infected with carbapenem-resistant $K$. pneumoniae [55]. The combination of doripenem and ertapenem has also exhibited a greater efficacy than doripenem alone at $72 \mathrm{~h}$ for KPCproducing $K$. pneumoniae infection in a neutropenic murine model with thigh infection [62].

The synergistic effects of DCT regimens mainly focus on the mechanism in combination with ertapenem. Ertapenem is considered to be the most sensitive to KPC enzyme in carbapenem antibiotics [63]. It can be hypothesized that ertapenem has preferential affinity with KPC and can consume the carbapenemases [55]. When ertapenem is combined with another carbapenem antibiotic, KPC is decreased per unit time so that another carbapenem antibiotic is hydrolyzed less. Higher concentration of another carbapenem antibiotic kills KPC-producing K. pneumoniae better [26]. An alternative explanation is that during treatment, ertapenem decreases the initial inoculum density by acting as a suicide substrate, thereby permitting doripenem to express its successful activity against an already reduced and manageable inoculum [64]. However, an in vitro study [59] has indicated that in DCT, the imipenem-containing combinations show the most efficacy in the treatment for

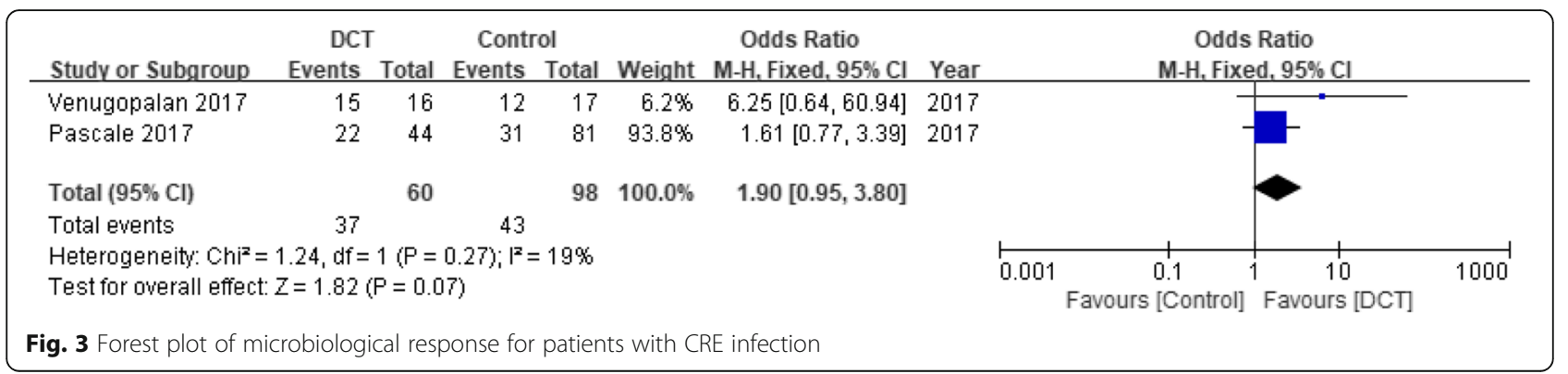




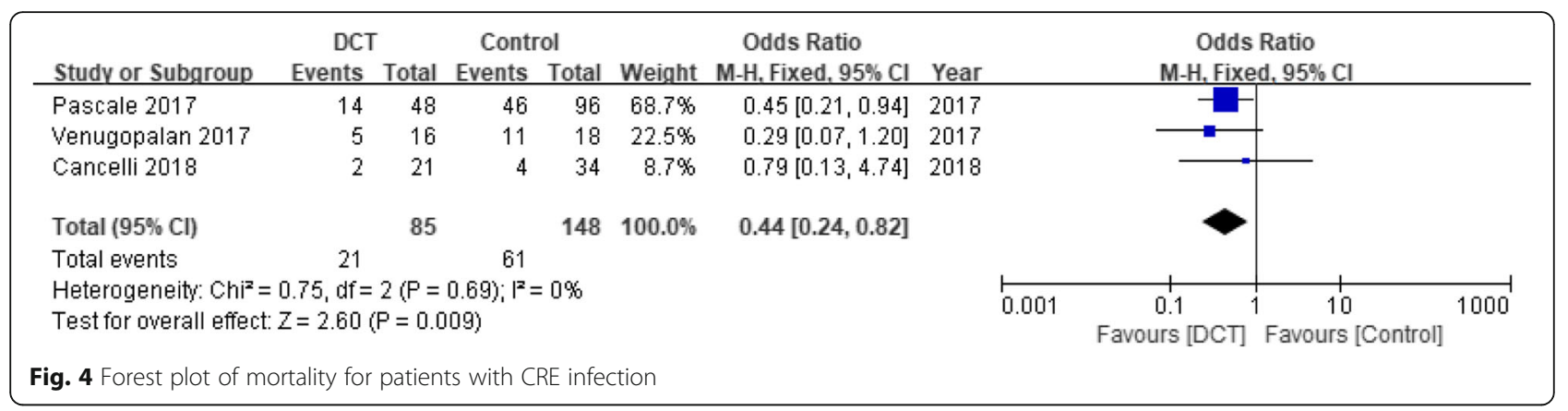

carbapenemase-producing $K$. pneumoniae infection, while ertapenem may not be the best option to inactivate carbapenemases. This may be related to particularly enhanced in vitro activity of imipenem-containing combinations, even imipenem at sub-inhibitory concentrations [65]. However, in vivo data on imipenem-containing DCT are limited, which may be attributed to the central nervous system toxicity of imipenem and short stability of intravenous preparation [56, 66]. Meanwhile, meropenem can synergistically exert antibacterial effects by binding to the bacterial target, especially if minimal inhibitory concentration (MIC) value of meropenem is $\leq 128 \mu \mathrm{g} / \mathrm{ml}$ [60]. Further investigation is required since the treatment mechanism of DCT has not been extensively explored.

Although all available clinical evidence was included, there were four limitations in our systematic review and meta-analysis. Firstly, the studies included in the metaanalysis were all cohort or case-control studies, with case series or case reports as a supplement. The three studies including patients with CRE infection were all retrospective. The grade of evidence was insufficient. Secondly, publication and selective bias might exist. Two of three studies were from Italy, increasing the risk of bias due to geographic reasons. Thirdly, all the included studies did not provide information of resistance changes of pathogens after DCT exposure. Therefore, we were unable to know if excessive carbapenem exposure would lead to greater carbapenem resistance. At last, none of the antibiotics in control groups involved novel beta-lactam/beta-lactamase inhibitors (such as ceftazidime/avibactam). It was hard to evaluate how DCT would exhibit compared with the novel antibiotics.

\section{Conclusions}

Collectively, due to similar efficacy response and lower mortality, DCT could be used as an alternative therapeutic option in the treatment of MDR Gram-negative bacterial infections. More high-quality clinical trials were required to further address the efficacy, safety and risk of carbapenem resistance of DCT.

\section{Abbreviations}

DCT: Double-carbapenem therapy; D: DCT group; C: The control group; PNA: Pneumonia; HAP: Hospital-acquired pneumonia; VAP: Ventilatorassociated pneumonia; BSI: Bloodstream infection; SBSI: Secondary bloodstream infection; CRBSI: Catheter-related bloodstream infection; API: Aortic periprosthetic infection; EPI: Endovascular prosthesis infection; EVDI: External ventricular drainage infection; CVCl: Central venous catheter infection; UTI: Urinary tract infection; IAI: Intra-abdominal infection; SSTI: Skin and soft tissue infection; STI: Soft tissue infection; SSSI: Skin and skin structure infection; SSI: Surgical site infection; MSI: Multiple site infection; KP: Klebsiella pneumoniae; EC: Escherichia coli; CRE: Carbapenem-resistant Enterobacteriaceae; CPCRE: Carbapenemase producing carbapenem-resistant Enterobacteriaceae; CRKP: Carbapenem-resistant K. pneumoniae;

CPKP: Carbapenemase-producing K. pneumoniae; KPC: K. pneumoniae carbapenemase; KPC-II: A type II carbapenemase against KPC-producers; KPCIII: A type III carbapenemase against KPC-producers; SME: Serratia marcescens enzyme; NMC: Non-metallo enzyme carbapenemase; IMI: Imipenemhydrolyzing; GES: Guiana extended spectrum; MBL: Metallo-beta-lactamase; IMP: Imipenemase; VIM: Verona integron-encoded MBL; SPM: Sao Paulo MBL; GIM: German imipenemase; NDM: New Delhi MBL; OXA: Oxacillinase; MDR: Multidrug resistant; XDR: Extensively drug resistant; PDR: Pandrug resistant; MEM: Meropenem; ETP: Ertapenem; DOR: Doripenem; GEN: Gentamicin; CST: Colistin; TGC: Tigecycline; RIF: Rifampicin; AMG: Aminoglycosides; CAB: Carbapenem antibiotics; FLQ: Fluoroquinolones; CIP: Ciprofloxacin; AMK: Amikacin; FOF: Fosfomycin; LZD: Linezolid; PMB: Polymyxin B; DOX: Doxycycline; FCA: Fluconazole; AVC: Ceftazidime/ avibactam; RCT: Randomized controlled trial; NOS: Newcastle-Ottawa Scale; MIC: Minimum inhibitory concentration; SD: Standard deviation; OR: Odds ratio; Cl: Confidence interval; S: Sensitive; I: Intermediate; R: Resistant

\section{Acknowledgements}

Not applicable.

\section{Authors' contributions}

RW and YC conceived and designed the research. YYL and JW made contributions to acquisition, analysis and interpretation of data. YYL, JW and YC drafted the article. RW and YC revised it critically for important intellectual content. All authors read and approved the final manuscript.

\section{Funding}

This work is supported by the National Natural Science Foundation of China [81573472, 81770004] and 13th Five-Year Plan of National Major Science and Technology Projects of China [2018ZX09201-013]. The funders have no roles in study design, data collection and analysis, decision to publish, or preparation of the manuscript.

\section{Availability of data and materials}

The datasets used or analyzed during this study are available from the corresponding author on reasonable requests.

Ethics approval and consent to participate Not applicable. 


\section{Consent for publication}

Not applicable.

\section{Competing interests}

There is no conflict of interest to be declared. The authors alone are responsible for the content and writing of the paper.

\section{Author details}

${ }^{1}$ Center of Medicine Clinical Research, Department of Pharmacy, PLA General Hospital, 28 Fu Xing Road, Beijing 100853, People's Republic of China. ${ }^{2}$ PLA Medical School, Beijing, China.

Received: 20 November 2019 Accepted: 1 June 2020

Published online: 11 June 2020

\section{References}

1. Asbel LE, Levison ME. Cephalosporins, carbapenems, and monobactams. Infect Dis Clin N Am. 2000;14(2):435-47 ix.

2. Jacoby GA, Munoz-Price LS. The new beta-lactamases. N Engl J Med. 2005; 352(4):380-91. https://doi.org/10.1056/NEJMra041359.

3. Tooke CL, Hinchliffe P, Bragginton EC, Colenso CK, Hirvonen VHA, Takebayashi Y, Spencer J. Beta-lactamases and beta-lactamase inhibitors in the 21st century. J Mol Biol. 2019. https://doi.org/10.1016/j.jmb.2019.04.002.

4. Bassetti M, Peghin M, Vena A, Giacobbe DR. Treatment of infections due to MDR gram-negative Bacteria. Front Med. 2019;6:74. https://doi.org/10.3389/ fmed.2019.00074.

5. Bonomo RA. Beta-lactamases: a focus on current challenges. Cold Spring Harbor Perspect Med. 2017;7(1). https://doi.org/10.1101/cshperspect. a025239.

6. Queenan AM, Bush K. Carbapenemases: the versatile beta-lactamases. Clin Microbiol Rev. 2007;20(3):440-58, table of contents. https://doi.org/10.1128/ cmr.00001-07.

7. Jean SS, Lee WS, Lam C, Hsu CW, Chen RJ, Hsueh PR. Carbapenemaseproducing gram-negative bacteria: current epidemics, antimicrobial susceptibility and treatment options. Future Microbiol. 2015;10(3):407-25. https://doi.org/10.2217/fmb.14.135.

8. Walther-Rasmussen J, Hoiby N. Class A carbapenemases. J Antimicrob Chemother. 2007;60(3):470-82. https://doi.org/10.1093/jac/dkm226.

9. Nordmann P, Poirel L, Toleman MA, Walsh TR. Does broad-spectrum betalactam resistance due to NDM-1 herald the end of the antibiotic era for treatment of infections caused by gram-negative bacteria? J Antimicrob Chemother. 2011;66(4):689-92. https://doi.org/10.1093/jac/dkq520.

10. Walsh TR, Toleman MA, Poirel L, Nordmann P. Metallo-beta-lactamases: the quiet before the storm? Clin Microbiol Rev. 2005;18(2):306-25. https://doi. org/10.1128/cmr.18.2.306-325.2005.

11. Karampatakis T, Antachopoulos C, Tsakris A, Roilides E. Molecular epidemiology of carbapenem-resistant Pseudomonas aeruginosa in an endemic area: comparison with global data. Eur J Clin Microbiol Infect Dis. 2018;37(7):1211-20. https://doi.org/10.1007/s10096-018-3244-4.

12. Bush $\mathrm{K}$, Jacoby GA. Updated functional classification of beta-lactamases. Antimicrob Agents Chemother. 2010;54(3):969-76. https://doi.org/10.1128/ aac.01009-09.

13. Poirel L, Potron A, Nordmann P. OXA-48-like carbapenemases: the phantom menace. J Antimicrob Chemother. 2012;67(7):1597-606. https://doi.org/10. 1093/jac/dks121.

14. Watkins RR, Deresinski S. Is combination therapy for carbapenem-resistant Klebsiella pneumoniae the new standard of care? Expert Rev Anti-Infect Ther. 2015;13(4):405-7. https://doi.org/10.1586/14787210.2015.1018825.

15. Tangden T, Giske CG. Global dissemination of extensively drug-resistant carbapenemase-producing Enterobacteriaceae: clinical perspectives on detection, treatment and infection control. J Intern Med. 2015;277(5):50112. https://doi.org/10.1111/joim.12342.

16. Zusman O, Altunin S, Koppel F, Dishon Benattar Y, Gedik H, Paul M. Polymyxin monotherapy or in combination against carbapenem-resistant bacteria: systematic review and meta-analysis. J Antimicrob Chemother. 2017;72(1):29-39. https://doi.org/10.1093/jac/dkw377.

17. Shields RK, Potoski BA, Haidar G, Hao B, Doi Y, Chen L, Press EG, Kreiswirth BN, Clancy CJ, Nguyen MH. Clinical outcomes, drug toxicity, and emergence of Ceftazidime-Avibactam resistance among patients treated for Carbapenem-resistant Enterobacteriaceae infections. Clin Infect Dis. 2016; 63(12):1615-8. https://doi.org/10.1093/cid/ciw636.
18. Jiao $Y$, Moya $B$, Chen MJ, Zavascki AP, Tsai $H$, Tao X, Sutaria DS, Louie A, Boyce JD, Lucas DD, Kim TH, Tsuji BT, Bonomo RA, Drusano GL, Bulitta JB. Comparable efficacy and better safety of double beta-lactam combination therapy versus beta-lactam plus aminoglycoside in gram-negatives: a metaanalysis of randomized, Controlled Trials. Antimicrob Agents Chemother. 2019. https://doi.org/10.1128/aac.00425-19.

19. Nabarro LE, Veeraraghavan B. Combination therapy for carbapenemresistant Enterobacteriaceae: increasing evidence, unanswered questions, potential solutions. Eur J Clin Microbiol Infect Dis. 2015;34(12):2307-11. https://doi.org/10.1007/s10096-015-2486-7.

20. Tangden T, Hickman RA, Forsberg P, Lagerback P, Giske CG, Cars O. Evaluation of double- and triple-antibiotic combinations for VIM- and NDM-producing Klebsiella pneumoniae by in vitro time-kill experiments. Antimicrob Agents Chemother. 2014;58(3):1757-62. https://doi.org/10.1128/aac.00741-13.

21. Medeiros GS, Rigatto MH, Falci DR, Zavascki AP. Combination therapy with polymyxin B for carbapenemase-producing Klebsiella pneumoniae bloodstream infection. Int J Antimicrob Agents. 2019;53(2):152-7. https:// doi.org/10.1016/j.jjantimicag.2018.10.010.

22. Khawcharoenporn T, Chuncharunee A, Maluangnon C, Taweesakulvashra T, Tiamsak P. Active monotherapy and combination therapy for extensively drug-resistant Pseudomonas aeruginosa pneumonia. Int J Antimicrob Agents. 2018;52(6):828-34. https://doi.org/10.1016/j.jjantimicag.2018.09.008.

23. Gutierrez-Gutierrez B, Salamanca E, de Cueto M, Hsueh PR, Viale P, PanoPardo JR, Venditti M, Tumbarello M, Daikos G, Canton R, Doi Y, Tuon FF, Karaiskos I, Perez-Nadales E, Schwaber MJ, Azap OK, Souli M, Roilides E, Pournaras S, Akova M, Perez F, Bermejo J, Oliver A, Almela M, Lowman W, Almirante B, Bonomo RA, Carmeli Y, Paterson DL, Pascual A, Rodriguez-Bano J. Effect of appropriate combination therapy on mortality of patients with bloodstream infections due to carbapenemase-producing Enterobacteriaceae (INCREMENT): a retrospective cohort study. Lancet Infect Dis. 2017;17(7):726-34. https://doi.org/10.1016/s1473-3099(17)30228-1.

24. Zusman O, Avni T, Leibovici L, Adler A, Friberg L, Stergiopoulou T, Carmeli Y, Paul M. Systematic review and meta-analysis of in vitro synergy of polymyxins and carbapenems. Antimicrob Agents Chemother. 2013;57(10): 5104-11. https://doi.org/10.1128/aac.01230-13.

25. Rees VE, Yadav R, Rogers KE, Bulitta JB, Wirth V, Oliver A, Boyce JD, Peleg AY, Nation RL, Landersdorfer CB. Meropenem combined with ciprofloxacin combats Hypermutable Pseudomonas aeruginosa from respiratory infections of cystic fibrosis patients. Antimicrob Agents Chemother. 2018; 62(11). https://doi.org/10.1128/aac.01150-18.

26. Giamarellou H, Galani L, Baziaka F, Karaiskos I. Effectiveness of a doublecarbapenem regimen for infections in humans due to carbapenemaseproducing pandrug-resistant Klebsiella pneumoniae. Antimicrob Agents Chemother. 2013;57(5):2388-90. https://doi.org/10.1128/aac.02399-12.

27. Moher D, Liberati A, Tetzlaff J, Altman DG. Preferred reporting items for systematic reviews and meta-analyses: the PRISMA statement. BMJ (Clinical research ed). 2009;339:b2535. https://doi.org/10.1136/bmj.b2535.

28. Cai Y, Li YY (2019) Double carbapenem therapy in the treatment of severe gram-negative bacteria infections: a systematic review and meta-analysis. Available at: https://wwwcrdyorkacuk/PROSPERO:CRD42019129979.

29. Higgins JP, Altman DG, Gotzsche PC, Juni P, Moher D, Oxman AD, Savovic J, Schulz KF, Weeks L, Sterne JA. The Cochrane Collaboration's tool for assessing risk of bias in randomised trials. BMJ (Clinical research ed). 2011; 343:d5928. https://doi.org/10.1136/bmj.d5928.

30. Stang A. Critical evaluation of the Newcastle-Ottawa scale for the assessment of the quality of nonrandomized studies in meta-analyses. Eur J Epidemiol. 2010;25(9):603-5. https://doi.org/10.1007/s10654-010-9491-z.

31. Higgins JP, Thompson SG, Spiegelhalter DJ. A re-evaluation of randomeffects meta-analysis. J R Stat Soc A, (Statistics in Society). 2009;172(1):13759. https://doi.org/10.1111/j.1467-985X.2008.00552.x.

32. Higgins JP, Thompson SG, Deeks JJ, Altman DG. Measuring inconsistency in meta-analyses. BMJ (Clinical research ed). 2003;327(7414):557-60. https://doi. org/10.1136/bmj.327.7414.557.

33. De Pascale G, Martucci G, Montini L, Panarello G, Cutuli SL, Di Carlo D, Di Gravio V, Di Stefano R, Capitanio G, Vallecoccia MS, Polidori P, Spanu T, Arcadipane A, Antonelli M. Double carbapenem as a rescue strategy for the treatment of severe carbapenemase-producing Klebsiella pneumoniae infections: a two-center, matched case-control study. Critical Care (London, England). 2017;21 (1):173. https://doi.org/10.1186/s13054-017-1769-z.

34. Venugopalan V, Nogid B, Le TN, Rahman SM, Bias TE. Double carbapenem therapy (DCT) for bacteremia due to carbapenem-resistant Klebsiella 
pneumoniae (CRKP): from test tube to clinical practice. Infect Dis (London, England). 2017;49(11-12):867-70. https://doi.org/10.1080/23744235.2017. 1350880.

35. Cancelli F, Oliva A, De Angelis M, Mascellino MT, Mastroianni CM, Vullo V. Role of double-Carbapenem regimen in the treatment of infections due to Carbapenemase producing Carbapenem-resistant Enterobacteriaceae: a single-center, observational study. Biomed Res Int. 2018;2018:2785696. https://doi.org/10.1155/2018/2785696.

36. El Nekidy WS, Mooty MY, Attallah N, Cardona L, Bonilla MF, Ghazi IM. Successful treatment of multidrug resistant Klebsiella pneumoniae using dual carbapenem regimen in immunocompromised patient. IDCases. 2017; 9:53-5. https://doi.org/10.1016/j.idcr.2017.06.005.

37. Oliva A, Mascellino MT, Cipolla A, D'Abramo A, De Rosa A, Savinelli S, Ciardi MR, Mastroianni CM, Vullo V. Therapeutic strategy for pandrug-resistant Klebsiella pneumoniae severe infections: short-course treatment with colistin increases the in vivo and in vitro activity of double carbapenem regimen. Int J Infect Dis. 2015;33:132-4. https://doi.org/10.1016/j.jijid.2015.01. 011.

38. Oliva A, D'Abramo A, D'Agostino C, lannetta M, Mascellino MT, Gallinelli C, Mastroianni CM, Vullo V. Synergistic activity and effectiveness of a doublecarbapenem regimen in pandrug-resistant Klebsiella pneumoniae bloodstream infections. J Antimicrob Chemother. 2014;69(6):1718-20. https://doi.org/10.1093/jac/dku027.

39. Oliva A, Cipolla A, Gizzi F, D'Abramo A, Favaro M, De Angelis M, Ferretti G, Russo G, lannetta M, Mastroianni CM, Mascellino MT, Vullo V. Severe bloodstream infection due to KPC-producer E coli in a renal transplant recipient treated with the double-Carbapenem regimen and analysis of in vitro synergy testing: a case report. Medicine. 2016;95(7):e2243. https:// doi.org/10.1097/md.0000000000002243.

40. Montelione N, Menna D, Sirignano P, Capoccia L, Mansour W, Speziale F. Open conversion after aortic Endograft infection caused by Colistinresistant, Carbapenemase-producing Klebsiella pneumoniae. Tex Heart Inst J. 2016;43(5):453-7. https://doi.org/10.14503/thij-15-5265.

41. Chua NG, Zhou YP, Tan TT, Lingegowda PB, Lee W, Lim TP, Teo J, Cai Y, Kwa AL. Polymyxin B with dual carbapenem combination therapy against carbapenemase-producing Klebsiella pneumoniae. J Inf Secur. 2015;70(3): 309-11. https://doi.org/10.1016/j.jinf.2014.10.001.

42. Piedra-Carrasco N, Miguel L, Fabrega A, Vinado B, Campany D, Mir A, Fox ML, Almirante B, Larrosa N, Ruiz-Camps I, Gonzalez-Lopez JJ. Effectiveness of a double-Carbapenem regimen in a KPC-producing Klebsiella pneumoniae infection in an Immunocompromised patient. Microbial Drug Resist (Larchmont, NY). 2018;24(2):199-202. https://doi.org/10.1089/mdr.2017.0129.

43. Galvao LM, Oliveira APR, Ibanes AS, Monteiro J, Inoue F, Dantas DC, Sanchez F, Santos DW, Abboud CS. Fatal case of donor-derived colistin-resistant carbapenemase-producing Klebsiella pneumoniae transmission in cardiac transplantation. Braz J Infect Dis. 2018;22(3):235-8. https://doi.org/10.1016/j. bjid.2018.04.005

44. Tanir Basaranoglu S, Ozsurekci Y, Aykac K, Arikan KO, Buyukcam A, Cengiz $A B$, Ceyhan M, Kara A. Add-on therapy with Ertapenem in infections with multidrug resistant gram-negative Bacteria: pediatric experience. Case Rep Infect Dis. 2017;2017:8096420. https://doi.org/10.1155/2017/8096420.

45. Souli M, Karaiskos I, Masgala A, Galani L, Barmpouti E, Giamarellou H. Double-carbapenem combination as salvage therapy for untreatable infections by KPC-2-producing Klebsiella pneumoniae. Eur J Clin Microbiol Infect Dis. 2017;36(7):1305-15. https://doi.org/10.1007/s10096-017-2936-5.

46. Oliva A, Gizzi F, Mascellino MT, Cipolla A, D'Abramo A, D'Agostino C, Trinchieri V, Russo G, Tierno F, lannetta M, Mastroianni CM, Vullo V. Bactericidal and synergistic activity of double-carbapenem regimen for infections caused by carbapenemase-producing Klebsiella pneumoniae. Clin Microbiol Infect. 2016;22(2):147-53. https://doi.org/10.1016/j.cmi.2015.09.014.

47. Cprek JB, Gallagher JC. Ertapenem-containing double-Carbapenem therapy for treatment of infections caused by Carbapenem-resistant Klebsiella pneumoniae. Antimicrob Agents Chemother. 2016;60(1):669-73. https://doi. org/10.1128/aac.01569-15.

48. Liang HY, Dong YM, Yuan J. Clinical pharmacists participating in one case of double-carbapenem in the treatment of pan-resistant Klebsiella pneumoniae bloodstream infection. J Guangdong Pharm Univ. 2018;34(1): $82-4$.

49. Rosa R, Rudin SD, Rojas LJ, Hujer AM, Perez-Cardona A, Perez F, Bonomo RA, Martinez O, Abbo LM, Camargo JF. "double carbapenem" and oral fosfomycin for the treatment of complicated urinary tract infections caused by blaNDM -harboring Enterobacteriaceae in kidney transplantation. Transpl Infect Dis. 2018;20(1). https://doi.org/10.1111/tid.12795.

50. Tumbarello M, Trecarichi EM, De Rosa FG, Giannella M, Giacobbe DR, Bassetti M, Losito AR, Bartoletti M, Del Bono V, Corcione S, Maiuro G, Tedeschi S, Celani L, Cardellino CS, Spanu T, Marchese A, Ambretti S, Cauda R, Viscoli C, Viale P. Infections caused by KPC-producing Klebsiella pneumoniae: differences in therapy and mortality in a multicentre study. J Antimicrob Chemother. 2015;70(7):2133-43. https://doi.org/10.1093/jac/ dkv086.

51. Ceccarelli G, Falcone M, Giordano A, Mezzatesta ML, Caio C, Stefani S, Venditti M. Successful ertapenem-doripenem combination treatment of bacteremic ventilator-associated pneumonia due to colistin-resistant KPCproducing Klebsiella pneumoniae. Antimicrob Agents Chemother. 2013; 57(6):2900-1. https://doi.org/10.1128/aac.00188-13.

52. Camargo JF, Simkins J, Beduschi T, Tekin A, Aragon L, Perez-Cardona A, Prado CE, Morris MI, Abbo LM, Canton R. Successful treatment of Carbapenemase-producing Pandrug-resistant Klebsiella pneumoniae bacteremia. Antimicrob Agents Chemother. 2015;59(10):5903-8. https://doi. org/10.1128/aac.00655-15.

53. Wells GA, Shea B, O'Connell D, Peterson J, Welch V, Losos M (2013) The Newcastle-Ottawa Scale (NOS) for assessing the quality of nonrandomised studies in meta-analyses. Available at: http://wwwohrica/programs/clinical_ epidemiology/oxfordhtm.

54. Cook DA, Reed DA. Appraising the quality of medical education research methods: the medical education research study quality instrument and the Newcastle-Ottawa scale-education. Acad Med. 2015;90(8):1067-76. https:// doi.org/10.1097/acm.0000000000000786.

55. Bulik CC, Nicolau DP. Double-carbapenem therapy for carbapenemaseproducing Klebsiella pneumoniae. Antimicrob Agents Chemother. 2011; 55(6):3002-4. https://doi.org/10.1128/aac.01420-10.

56. Mashni O, Nazer L, Le J. Critical review of double-Carbapenem therapy for the treatment of Carbapenemase-producing Klebsiella pneumoniae. Ann Pharmacother. 2019;53(1):70-81. https://doi.org/10.1177/1060028018790573.

57. White BP, Patel S, Tsui J, Chastain DB. Adding double carbapenem therapy to the armamentarium against carbapenem-resistant Enterobacteriaceae bloodstream infections. Infect Dis (London, England). 2019;51(3):161-7. https://doi.org/10.1080/23744235.2018.1527470.

58. Oliva A, Scorzolini L, Castaldi D, Gizzi F, De Angelis M, Storto M, D'Abramo A, Aloj F, Mascellino MT, Mastroianni CM, Vullo V. Double-carbapenem regimen, alone or in combination with colistin, in the treatment of infections caused by carbapenem-resistant Klebsiella pneumoniae (CR-Kp). J Inf Secur. 2017;74(1):103-6. https://doi.org/10.1016/j.jinf.2016.10.002.

59. Poirel L, Kieffer N, Nordmann P. In vitro evaluation of dual carbapenem combinations against carbapenemase-producing Enterobacteriaceae. J Antimicrob Chemother. 2016;71(1):156-61. https://doi.org/10.1093/jac/ dkv294.

60. Oliva A, Scorzolini L, Cipolla A, Mascellino MT, Cancelli F, Castaldi D, D'Abramo A, D'Agostino C, Russo G, Ciardi MR, Mastroianni CM, Vullo V. In vitro evaluation of different antimicrobial combinations against carbapenemaseproducing Klebsiella pneumoniae: the activity of the double-carbapenem regimen is related to meropenem MIC value. J Antimicrob Chemother. 2017; 72(7):1981-4. https://doi.org/10.1093/jac/dkx084.

61. Fredborg M, Sondergaard TE, Wang M. Synergistic activities of meropenem double and triple combinations against carbapenemase-producing Enterobacteriaceae. Diagn Microbiol Infect Dis. 2017;88(4):355-60. https:// doi.org/10.1016/j.diagmicrobio.2017.04.015.

62. Wiskirchen DE, Crandon JL, Nicolau DP. Impact of various conditions on the efficacy of dual carbapenem therapy against KPC-producing Klebsiella pneumoniae. Int J Antimicrob Agents. 2013;41(6):582-5. https://doi.org/10. 1016/j.jiantimicag.2013.02.015.

63. Anderson KF, Lonsway DR, Rasheed JK, Biddle J, Jensen B, McDougal LK, Carey RB, Thompson A, Stocker S, Limbago B, Patel JB. Evaluation of methods to identify the Klebsiella pneumoniae carbapenemase in Enterobacteriaceae. J Clin Microbiol. 2007:45(8):2723-5. https://doi.org/10. 1128/jcm.00015-07.

64. Thomson KS. Double-carbapenem therapy not proven to be more active than carbapenem monotherapy against KPC-positive Klebsiella pneumoniae. Antimicrob Agents Chemother. 2012;56(7):4037; author reply 4038. https:// doi.org/10.1128/aac.06409-11.

65. Galani I, Nafplioti K, Chatzikonstantinou M, Souli M. In vitro evaluation of double-carbapenem combinations against OXA-48-producing Klebsiella 
pneumoniae isolates using time-kill studies. J Med Microbiol. 2018. https:/ doi.org/10.1099/jmm.0.000725.

66. Cannon JP, Lee TA, Clark NM, Setlak P, Grim SA. The risk of seizures among the carbapenems: a meta-analysis. J Antimicrob Chemother. 2014;69(8): 2043-55. https://doi.org/10.1093/jac/dku1 11.

\section{Publisher's Note}

Springer Nature remains neutral with regard to jurisdictional claims in published maps and institutional affiliations.

Ready to submit your research? Choose BMC and benefit from:

- fast, convenient online submission

- thorough peer review by experienced researchers in your field

- rapid publication on acceptance

- support for research data, including large and complex data types

- gold Open Access which fosters wider collaboration and increased citations

- maximum visibility for your research: over $100 \mathrm{M}$ website views per year

At $B M C$, research is always in progress.

Learn more biomedcentral.com/submissions 